\title{
Refractory anemia with excess blasts
}

INSERM

\section{Source}

INSERM. (1999). Orphanet: an online rare disease and orphan drug data base. Refractory anemia with excess blasts. ORPHA:86839

Refractory anemia with excess blasts (RAEB) is a frequent severe subtype of myelodysplastic syndrome (MDS; see this term) characterized by cytopenias with unilineage or multilineage dysplasia and 5\% to $19 \%$ blasts in bone marrow or blood. 